\title{
Spontaneous reattachment of total exudative retinal detachment in Coats' disease
}

\author{
Anamika Patel, Bhavik Panchal, ${ }^{\oplus}$ Avinash Pathengay
}

Vitreoretina and Uveitis Services, LV Prasad Eye Institute, Visakhapatnam, Andhra Pradesh, India

\section{Correspondence to} Dr Bhavik Panchal, drbhavikpanchal@gmail.com

$\mathrm{AP}$ and $\mathrm{BP}$ contributed equally.

Accepted 31 March 2019

\section{DESCRIPTION}

A 6-year-old boy presented to us with conditions of right eye diminution of vision associated with exotropia. The exotropia was noted at the age of 3 ; however, the diminution of vision was observed only 2 weeks prior to the presentation. On examination, the best corrected visual acuity (BCVA) was $20 / 500$ in the right eye and 20/20 in the left eye. A relative afferent pupillary defect was noted in the right eye. Slit lamp biomicroscopy showed a clear lens and a bullous exudative retinal detachment (RD) along with retinal telangiectasias and microaneurysms, and hard exudates were also seen behind the lens (figure 1). The left eye ocular examination was unremarkable. The intraocular pressure (IOP) in both eyes was 10 and $12 \mathrm{~mm} \mathrm{Hg}$, respectively.

A diagnosis of Coats' disease with total RD (stage 3B) was made in the right eye. Retinoblastoma, a possible differential diagnosis, was ruled out as the ultrasound B scan did not show any mass lesion or calcification. It was noted that the RD was not associated with choroidal detachment. Right eye subretinal fluid drainage along with intravitreal steroid injection was advised. However, the patient's parents preferred not to receive treatment then.

Later, the patient was lost to follow-up but returned after 1 year. The exotropia in the right eye persisted and the BCVA was counting fingers close to the face in the right eye and 20/20 in the left eye. Slit lamp biomicroscopy in the right eye showed a clear lens with haze in the anterior vitreous face. Fundus examination showed the presence of a spontaneously attached retina with multiple intraretinal haemorrhages, massive subretinal exudation in different stages of resolution and subretinal bands with hyperpigmented chorioretinal atrophy. Ocular coherence tomography showed the presence of hyper-reflective material in the outer retinal layers corresponding to the hard exudates, thinning of choriocapillaris and a subfoveal scar (figure 2). The left eye examination was unremarkable and the

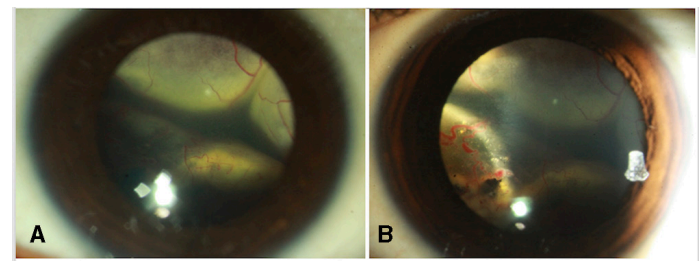

Figure 1 (A) Slit-lamp photograph of the right eye showed a massive exudative retinal detachment, seen behind the clear crystalline lens. (B) Retinal telangiectatic vessels can be seen on the detached retina behind the posterior lens capsule along with subretinal exudation.
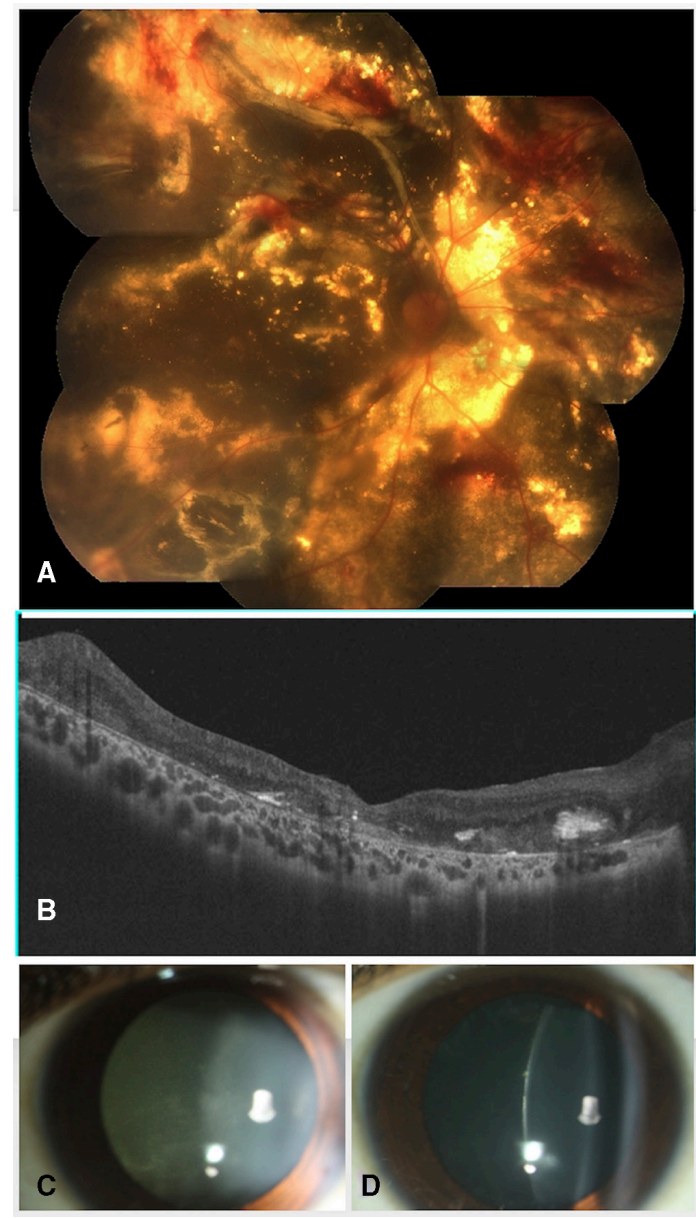

Figure 2 (A) The colour fundus photograph of the right eye showed a spontaneously attached retina with intraretinal haemorrhages, massive subretinal exudation in different stages of resolution and subretinal bands with hyperpigmented chorioretinal atrophy. (B) OCT shows hyper-reflective material in the outer retinal layers corresponding to the hard exudates, along with subfoveal subretinal scar. The choriocapillaris appears thinned out. (C) Slit-lamp image of the anterior segment indicates anterior vitreous haze. (D) The clear crystalline lens. OCT, ocular coherence tomography.

IOP was within normal limits in both the eyes. The child was asked to follow-up after 6 months. At the last follow-up, 2 years from the presentation, the retina was attached, and no recurrence was noted.

Coats' disease is a vascular abnormality, which is defined as an idiopathic retinal telangiectasia with intraretinal and/or subretinal exudation in the absence of retinal or vitreal traction. ${ }^{1}$ It usually occurs unilaterally in young males. The course of the disease is highly variable ranging from a 
quiescent stage to stage 4 , in which rubeosis iridis develops, causing neovascular glaucoma and a painful blind eye. This may require either enucleation or phthisis bulbi. ${ }^{2}$ While regression of Coats' disease with laser photocoagulation, cryotherapy, intravitreal steroids or anti-vascular endothelial growth factor therapy is well known, the spontaneous reattachment of retina after total RD is extremely rare. ${ }^{3-5}$ The possible explanation for such spontaneous reattachment of a massive exudative RD could be a reduction in the exudation by the abnormal telangiectatic vessels as well as the retinal pigment epithelium pump mechanism working favourably to eliminate the subretinal fluid. ${ }^{5}$ These probable explanations can at best be conjecture as the cause for the reduction in the activity of the abnormal telangiectatic vessels remains unknown.

\section{Learning points}

Coats' disease is a vascular abnormality occurring unilaterally in young males, characterised by idiopathic retinal telangiectasia, exudation and exudative retinal detachment (RD).

- Retinoblastoma should be ruled out in a child presenting with exudative RD.

- Massive exudative detachment touching the lens is not uncommonly seen in Coats' disease, and spontaneous reattachment of such detachments may occur.
Contributors AnP: initial preparation of the entire manuscript and compilation of contributions from other authors, and reviewed the requirements and guidelines for submission and designed the template accordingly. BP: contributed in establishing the diagnosis and management of the patient as a retina consultant, extensive literature search of similar cases, writing the case presentation, revision of the manuscript, citation management and editing of images. AvP: served as the chief of the division and supervised all the authors, set up the timeline for submission, planning the submission to BMJ, reviewed the requirements, critical revision of the article at every stage, drafted the take-home messages and gave final approval of the version to be submitted.

Funding The authors have not declared a specific grant for this research from any funding agency in the public, commercial or not-for-profit sectors.

Competing interests None declared.

Patient consent for publication Parental/guardian consent obtained.

Provenance and peer review Not commissioned; externally peer reviewed.

\section{REFERENCES}

1 Shields JA, Shields CL, Honavar SG, et al. Clinical variations and complications of Coats disease in 150 cases: the 2000 Sanford Gifford Memorial Lecture. Am J Ophthalmol 2001;131:561-71.

2 Shields JA, Shields CL, Honavar SG, et al. Classification and management of Coats disease: the 2000 Proctor Lecture. Am J Ophthalmol 2001;131:572-83.

3 Ozdek SC, Erdinc T, Kagnici B. Spontaneous regression in two unusual cases of advanced Coats' disease. J Pediatr Ophthalmol Strabismus 2011;48:e1-4.

4 Daniels $A B$, Brodie SE, Abramson DH. Spontaneous resolution of total retinal detachment in coats disease. Retin Cases Brief Rep 2010;4:206-9.

5 Ochi R, Sato B, Mimura M, et al. A case of coats' disease with spontaneous retinal reattachment after total detachment. Case Rep Ophthalmol 2015;6:200-3.

Copyright 2019 BMJ Publishing Group. All rights reserved. For permission to reuse any of this content visit https://www.bmj.com/company/products-services/rights-and-licensing/permissions/

BMJ Case Report Fellows may re-use this article for personal use and teaching without any further permission.

Become a Fellow of BMJ Case Reports today and you can:

- Submit as many cases as you like

- Enjoy fast sympathetic peer review and rapid publication of accepted articles

- Access all the published articles

- Re-use any of the published material for personal use and teaching without further permission

For information on Institutional Fellowships contact consortiasales@bmjgroup.com

Visit casereports.bmj.com for more articles like this and to become a Fellow 